\title{
A fuzzy TOPSIS method to rank effective fuel reduction factors: A case study of aviation companies
}

\author{
Javad Siahkali Moradi $^{\mathrm{a}^{*}}$, Davood Rafeierad ${ }^{\mathrm{b}}$, and Arezoo Nazar Ahari ${ }^{\mathrm{a}}$
}

${ }^{a}$ Department of Management, Islamic Azad University, Science and Research Branch, Tehran, Iran

${ }^{b}$ Department of Management and Accounting, Allameh Tabatabaee University, Tehran, Iran

\begin{tabular}{l}
\hline A R T I C L E I N F O \\
\hline Article history: \\
Received March 20, 2011 \\
Received in Revised form \\
June, 10, 2011 \\
Accepted 12 June 2011 \\
Available online \\
14 June 2011 \\
\hline Keywords: \\
Fuzzy TOPSIS \\
Aviation \\
Fuel price \\
Fuel consumption \\
Aircraft companies \\
\hline
\end{tabular}
A B S T R A C T

\begin{abstract}
Aviation fuel of aircrafts is one of the most important and predominant expenditures in air companies. The recent jump on petroleum price has increased the price of equipments and maintenance. Therefore, many aircraft companies look for different ways to reduce their expenditures as much as they can. In this article, we study effective factors to reduce the fuel consumption. The proposed study of this paper gathers different criteria, which are important for cost reduction plans based on experts' point of view. We take advantages of quantitative and qualitative characteristics of criteria and experts' ideas using fuzzy decision making. Finally, a list of effective factors to reduce the fuel consumption is presented based on order of their importance.
\end{abstract}

(c) 2011 Growing Science Ltd. All rights reserved.

\section{Introduction}

Transportation plays an important role on economic growth of any country. There are different forms of transportations such as road, railway and airway transportation. Air transportation is considered as one of the fastest and safest ways of transporting goods and services across the world. Air transportation normally needs significant amount of investment and it requires substantial cost items to maintain the infrastructures. One of the most important and predominant expenditure of them is aviation fuel consumption (Carter, 2002). Therefore, we need to monitor different factors affecting aviation fuel consumption very carefully. The aircraft industry has been monopolized by some limited countries and in case of political conflict between the aircraft suppliers and other countries there may shortages on aircraft parts in some countries. When there is a sanction on an industry, there must be systematic maintenance engineering programs to reduce the risk of having unpredictable male function on important aircraft parts and components. The steady trend of increase on population would also increase demands for air transportation. This also increases the transportation and growth of fuel consumption in different parts including airy transportation. On the other hand, the increase in competition would also forces the aircraft companies to reduce the fuel consumption. During the past

* Corresponding author. Tel: +989122520885

E-mail addresses: syhkaly@yahoo.com (J. Siahkali Moradi) 
ten years, price of unrefined petroleum has increased five folds from $20 \$$ per liter to over $80 \$$. Any reduction on fuel consumption not only reduces the aircraft expenditures but also it helps maintain better environment (Van der Burgt, 1989; Marchetti, 1982). There are different evidences to believe that aircraft fuel consumption is one of the major sources of Co2 emission (Ohsfeldt, 2007; Lister, 1992). There are many countries such as Iran, where domestic flights are over $80 \%$ of total flights.

\section{Assessment of effective factors in reduction of fuel consumption}

A comprehensive review on the existing literature reveals that there are many factors, which affect fuel consumption such as air traffic, transporting weight, distance and speed, maintenance engineering, dynamic flight capabilities, advances on design of technology, etc. There are many technological specifications, which also influence fuel consumption such as flight altitude, power of propulsion, payload of wings, motor fuel consumption and aircraft speed. The accurate selection of motor is a primary key on designing aircraft, which is the basis of supplies for designing and providing suitable characteristics and customer demands (Carter, 2002). These characteristics are as follows,

1. Suitable power on motor on takeoff time and the terms of environment temperature,

2. Appropriate horizontal speed,

3. Motor weight,

4. Fuel consumption on particular motor,

5. Characteristics of turbine and compressor.

The weights of aircraft include the weights of aircraft chairs, cabin equipment, kitting and air bags, etc. Obviously, any reduction on weights could help fuel saving, which increases the efficiency of aircraft industry (Ohsfeldt, 2007). We may reduce weights based on different techniques such as changing the chair quality by using carbonic chairs or by changing flight equipment, etc. Another factor on reducing the weight is when the flights are scheduled during the night when passengers maintain minimum movement and prefer to relax or sleep. The other issue affecting the weight is the position of cargo in flights, which could reduce fuel consumption whenever the cargos are properly positioned. Height of flight is another effective factor in reducing the amount of fuel consumption. Whenever a flight uses higher altitude, it consumes more fuel energy (Douglas, 1992). On the other hand, when a flight maintains a relatively high altitude, there is a higher pressure on passengers, which reduces consumer satisfaction (Williams, 2002). Weather conditions and environmental temperature are the other effective and important factors in fuel consumption. For instance, when the temperature of environment is very high and weather is warm, we should make more pressure to the motor of aircraft in order to make the best performance, which increases fuel consumption; as a result, fuel consumption in warm seasons is more than cold seasons (Williams, 2002).

Suitable amount of air molecules are needed to be attracted to establish aircraft motor. In fact during some seasons such as summer when the weather is warm the distribution of air molecules is accompanied with more pressure which increases fuel consumption. This issue is alleviated during the cold season and aircraft needs less fuel consumption. Another important factor is direction of wind on aircraft, which are divided in two different parts. The first one is associated with the wind that blows from forwards and strikes with aircraft and the second one is the that blows from backwards and strikes with the aircraft from back (Williams, 2005). If the wind supports an aircraft from the back it will reduce the fuel consumption, significantly since it helps to aircraft movement, increase its speed, reduce time of flight, course concerned destinations in a little time and reduce fuel consumption. However, the existence of wind from forward is very important for taking off and landing aircraft. At the time of landing, wind should blow from forward in order that aircraft lands smoothly. When wind blows from backward, it puts more pleasure on aircraft to go forward; so 
aircraft cannot reduce its speed and stop, smoothly. As a result, pilot should select a suitable distance to prevent any possible damage on aircraft and optimize fuel consumption (Williams, 2005).

As we can observe, there are several factors effecting the fuel consumption with various impact. There are different studies based on gathering decision maker's feedbacks. A good study on these factors help experts have better planning for reduction of fuel consumption and focus on more important factors. Today, Commercial aircrafts are made based on three different motors; namely full water turbo, turbo fan and turbo jet. Principally, turbo fan motors consume lower fuel compared with other two engines. Even turbo fan motors consume lower fuel in contrast with jet motors. Indeed, turbo fan and turbo jet have capacity of producing higher trusts and flight in more heights and speeds, but they are noisy compared with other two engines of turbo jet and turbo fan (Williams, 2005). Our survey indicates that most of the flights are executed with turbo jets.

In addition to kind of motor, there are other factors among: characteristics of mission like height of flight, numbers of chairs, and length of runway and etc effect on total function of aircraft concerning fuel consumption. Selecting suitable aircraft with length of distance is very important. As we explained earlier, about $80 \%$ of all journey flights are specialized to internal flights and approximately $65 \%$ of all airy fuels are consumed in internal flights. Therefore, assessing method of fuel consumption and presenting reductive methods of its rate in internal flights have special priority (Graham, 1951).

One of characteristics of internal flights concerning fuel consumption is the conformity of aircraft kind and model with the length of distance (Reynolds, 2008). All different factors in designing aircraft cause to decrease rate of fuel consumption in terms of length increase.

The following four factors have been recommended by many experts to reduce fuel consumption,

1. Usage of full water turbo for short distances.

2. Modernization and advancement of airy traffic management,

3. Encouragement of pilots consuming lower fuel,

4. Reduction of prohibited areas in flight distance of aircraft.

Therefore, using suitable aircraft can remarkably reduce fuel consumption (Reynolds, 2008). Among principle solutions in reducing fuel consumption in air sector, direction of aviation companies for using full water turbo aircrafts in short distances, assistance to internal production and promotion of qualitative character to their design can notably cause economy in fuel consumption.

\section{A proposed method for selecting production}

Selection matter of an alternative among several alternatives is a multi criterion decision making. Degree of incertitude, numbers of decision makers and nature of criterion are the issues which must be concerned, significantly. In the methods of classic multi criterion decision making, rank and weight of criteria are objectively and accurately recognized (Delgado et al. 1992; Hong Yoon, 1981; Coffman Vegopta, 1991).

TOPSIS is recognized as one of multi criterion decision making methods. It is possible to provide basis of selection products methods that can effectively face with these characteristics and selection of alternatives, having the lowest distance from positive ideal solution and the highest distance from negative ideal solution.

Under most of situations, complex data are unsuitable for modeling real events. Individual jurisdictions involving superiority is often ambiguous by Language and it cannot estimate their superiority with numeral rate (Bellman \& Zadeh 1970; Chen, 2000; Delgado et al. 1992; Harrah et al. 1996; Harrah- Viedma, 2000).

We may concentrate more on the context of technique for order preference by similarity to ideal solution (TOPSIS) in this article to provide a method for solving matters of production selection in 
Fuzzy environment (Chen, 2000).

Concerning Fuzzy sets in the data of decision making and process of team deciding, verbal variables are used to determine weights of all criteria and rank of alternative with regard to every criterion. We can turn matrix of decision making to a matrix of fuzzy decision making. According to TOPSIS method explained in this article, fuzzy positive ideal solution and fuzzy negative ideal solution are determined and then a method is used to account distances between two fuzzy ranks.

Through method of top, we can regularly account distance of every alternative from fuzzy positive ideal solution (FPIS) to fuzzy negative ideal solution (FNIS). Finally, a closeness coefficient is determined on the account of every alternative for ranking all alternatives. The highest rate of closeness coefficient shows that alternative is close to FPIS and is similarly far from ENIS. In this article, comparative weights of different criteria and ranking of qualitative criteria are considered as the verbal variables. Whereas verbal assessment approximates subjective jurisdiction of decision maker, we can properly consider subordinators of membership of linear trapezoid for removing ambiguity of this verbal assessment (Delgado et al., 1998; Harrah \& Harrah-Viedma, 2000). These verbal variables can be shown as trapezoid fuzzy numbers shown in Fig. 1 and Fig. 2. Comparative weights of every criterion can be distinguished through direct specialization or dual comparative (Cook 1992).

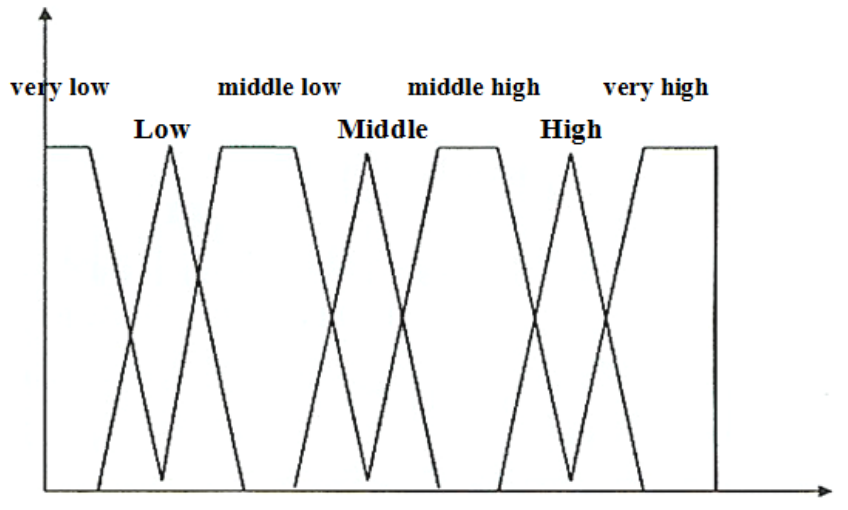

Fig. 1. Linguistic variables for determining weight of criteria

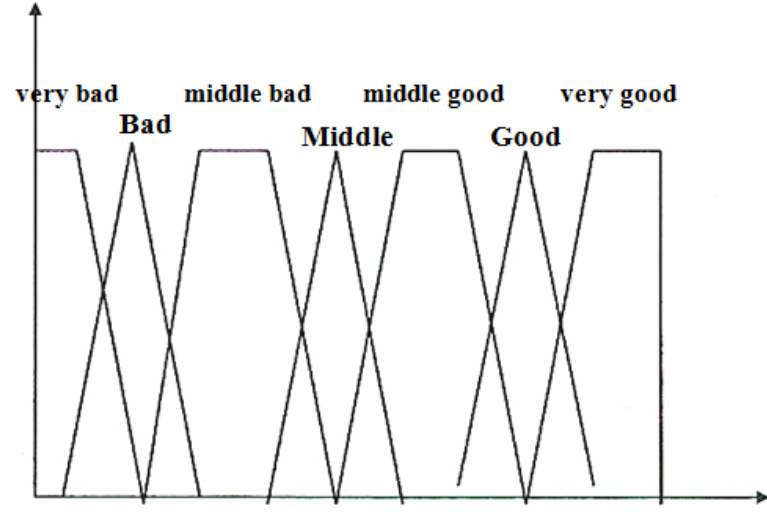

Fig. 2. Linguistic variables for determining ranks

It is suggested in this article that decision maker uses verbal variables, shown in Fig. 1 and Fig. 2 to evaluate the relative importance of all criteria and rank the alternatives based on qualitative criteria. For example, verbal variable of high medium (MH) and very good (VG) can be shown as (\%5, \%6, $\% 7$, and $\% 8)$ and $(8,9,9,10)$ and their membership functions can be represented as follows,

$$
\mu_{\text {Medium High }}(x)=\left\{\begin{array}{ll}
\circ, & x<0 / 5, \\
\frac{x-0.5}{0.6-0.5}, & 0.5 \leq x \leq 0.6, \\
1, & 0.6 \leq x \leq 0.7, \\
\frac{x-0.8}{0.7-0.8}, & 0.7 \leq x \leq 0.8, \\
0, & x>0.8 .
\end{array} \quad \mu_{\text {Very Good }}(x)= \begin{cases}0, & x<8, \\
\frac{x-8}{9-8}, & 8 \leq x \leq 9, \\
1, & 9 \leq x \leq 10 .\end{cases}\right.
$$

In fact, selection of factor can be a group multi criterion decision making that is possibly described with consideration of following collections:

1. A collection of $K$ decision maker called $E=\left\{D_{1}, D_{2}, D_{3}, \ldots, D_{k}\right\}$,

2. A collection of $M$ possible factor called $A=\left\{\mathrm{A}_{1}, \ldots \mathrm{A}_{\mathrm{m}}\right\}$,

3. A collection of $n$, criterion of $C_{j}=\left\{C_{1}, C 2, \ldots, C_{n}\right\}$, is accounted with process of every alternative, 4. A collection of function ranks of $A_{i}(i=1, \cdots, m)$ based on criteria of $X=\left\{X_{i j} i=1, \cdots, m j=1, \cdots, n\right\}$. Suppose we have a group of decision maker and fuzzy rank of every decision maker $D_{k}(k=1, \ldots, k)$ can 
be shown as trapezoid fuzzy numbers of $\tilde{R}_{k}(k=1, \cdots, K)$ by the membership subordinator. A suitable grouping method should consider every decision maker which means that fuzzy ranks of all decision makers of trapezoid fuzzy numbers are $R_{k}=\left(a_{k}, b_{k}, c_{k}, d_{k}\right)$. Then collective fuzzy rank can be defined as follows,

$$
\tilde{R}=(a, b, c, d), a=\min _{k}\left\{a_{k}\right\}, b=\frac{1}{k} \sum_{k=1}^{k} b_{k}, c=\frac{1}{k} \sum_{k=1}^{k} c_{k}, d=\max _{k}\left\{d_{k}\right\}, k=1,2, \ldots, k .
$$

Suppose that fuzzy rank and comparative weights of k decision maker are $\tilde{x}_{i j k}=\left(a_{i j k}, b_{i j k}, c_{i j k}, d_{i j k}\right)$, $\tilde{w}_{j k}=\left(w_{j k 1}, w_{j k 2}, w_{j k 3}, w_{j k 4}\right), i=1,2,, \ldots, n$. Hence, collective fuzzy numbers of $\tilde{x}_{i j k}$ alternatives are as follows,

$\tilde{x}_{i j}=\left(a_{i j}, b_{i j}, c_{i j}, d_{i j}\right), a_{i j}=\min _{k}\left\{a_{i j k}\right\}, b_{i j}=\frac{1}{K} \sum_{k=1}^{k} b_{i j k}, c_{i j}=\frac{1}{K} \sum_{k=1}^{k} c_{i j k}, d_{i j}=\max _{k}\left\{d_{i j k}\right\}$.

Collective weights of $\left(\tilde{w}_{j}\right)$ every criterion can be accounted as follows,

$\tilde{w}_{j}=\left(w_{j 1}, w_{j 2}, w_{j 3}, w_{j 4}\right), w_{j 1}=\min _{k}\left\{w_{j 1}\right\}, w_{j 2}=\frac{1}{K} \sum_{k=1}^{k} w_{j 2}, w_{j 3}=\frac{1}{K} \sum_{k=1}^{k} w_{j 3}, w_{j 4}=\max _{k}\left\{w_{j 4}\right\}$.

A selection matter of production can be exclusively shown in the model of matrix as follows,

$$
\tilde{D}=\left[\begin{array}{cccc}
\tilde{x}_{11} & \tilde{x}_{12} & \ldots & \tilde{x}_{1 n} \\
\tilde{x}_{21} & \tilde{x}_{21} & \ldots & \tilde{x}_{2 n} \\
\vdots & \vdots & \ldots & \vdots \\
\tilde{x}_{m 1} & \tilde{x}_{m 2} & \ldots & \tilde{x}_{m n}
\end{array}\right]
$$

In order to reduce the computations of $\tilde{x}_{i j}=\left(a_{i j}, b_{i j}, c_{i j}, d_{i j}\right)$ and $\tilde{w}_{j}=\left(w_{j 1}, w_{j 2}, w_{j 3}, w_{j 4}\right)$ in decision process, conversion of linear measure is used for converting measures of different criteria to the usable measure of profit criteria set (highest rank, highest operation) and expenditure criteria (lowest rank, highest operation). Therefore, normalized fuzzy decision matrix is as follows, $\tilde{R}=\left[\tilde{r}_{i j}\right]_{m \times n}$

Let $\mathrm{B}$ and $\mathrm{C}$ be the set of profit and expenditure criteria, then we have, $\tilde{r}_{i j}=\left(\frac{a_{i j}}{d_{j}^{*}}, \frac{b_{i j}}{d_{j}^{*}}, \frac{c_{i j}}{d_{j}^{*}}, \frac{d_{i j}}{d_{j}^{*}}\right), j \in B \quad \tilde{r}_{i j}=\left(\frac{a_{j}^{-}}{d_{i j}}, \frac{a_{j}^{-}}{c_{i j}}, \frac{a_{j}^{-}}{b_{i j}}, \frac{a_{j}^{-}}{a_{i j}}\right), j \in C d_{j}^{*}=\max _{i} d_{i j}, j \in B, a_{j}^{-}=\min _{i} a_{i j}, j \in C$

The normalization method given in Eq. (3) is used to protect the characteristics of $\tilde{r}_{i j} \forall i, j$. The weighted normalized fuzzy decision matrix is also calculated as $\tilde{V}=\left[\tilde{v}_{i j}\right]_{m \times n,} i=1,2, \ldots, m, j=1,2, \ldots, n$ where $\tilde{v}_{i j}=\tilde{r}_{i j}(.) \tilde{w}_{j}$. Therefore, fuzzy positive ideal solution- (FPIS, $\left.A^{*}\right)$ and fuzzy negative ideal solution (FNIS, $\left.A^{-}\right)$can be defined as follows,

$$
A^{*}=\left(\tilde{v}_{1}^{*}, \tilde{v}_{2}^{*}, \ldots, \tilde{v}_{n}^{*}\right), A^{-}=\left(\tilde{v}_{1}^{-}, \tilde{v}_{2}^{-}, \ldots, \tilde{v}_{n}^{-}\right), \tilde{v}_{j}^{*}=\max _{i}\left\{v_{i j 4}\right\}, \tilde{v}_{j}^{-}=\min _{i}\left\{v_{i j 1}\right\}, i=1,2, \ldots, m, j=1,2, \ldots, n \text {. }
$$

Distance of every alternative (factor) is calculated as follows,

$$
d_{i}^{*}=\sum_{j=1}^{n} d_{v}\left(\tilde{v}_{i j}, \tilde{v}_{j}^{*}\right), \quad i=1,2, \ldots, m, d_{i}^{-}=\sum_{j=1}^{n} d_{v}\left(\tilde{v}_{i j}, \tilde{v}_{j}^{-}\right), \quad i=1,2, \ldots, m
$$

The closeness coefficient of $\left(C C_{i}\right)$ for every alternative is as follows,

$$
C C_{i}=\frac{d_{i}^{-}}{d_{i}^{*}+d_{i}^{-}}, \quad i=1,2, \ldots, m \text {. }
$$

We distinguish regularity of all factors rankings and select the ones among justifiable factor set with 
regard to anticlimactic regularity of $C C_{i}$. Although we can recognize regularity of ranking of all justifiable factors, a more real process is probably used so that a verbal variable describe present evaluative manners of every production regarding its closeness coefficient. Regarding evaluative manners of every factor, we divide distance of $[0,1]$ to five distances which are summarized in Table 1.

Table 1

Suggested evaluation manners

\begin{tabular}{ll}
\hline Evaluative manners & Closeness coefficient $\left(C C_{i}\right)$ \\
\hline It is not suggested & $C C_{i} \in[0, .2)$ \\
It is suggested with the probable of high danger & $C C_{i} \in[0.2,0.4)$ \\
It is suggested with the probable of low danger & $C C_{i} \in[0.4,0.6)$ \\
It is suggested & $C C_{i} \in[0.6,0.8)$ \\
It is suggested and favored & $C C_{i} \in[0.8,1.0]$
\end{tabular}

If $\left(0,0.2\left[\in \mathrm{CC}_{\mathrm{i}}\right.\right.$, then factor $A_{\mathrm{i}}$ is possessed to the class of I and evaluation manners of factor $A_{i}$ is not suggested. If we have $\left(0.2,0.4\left[\in \mathrm{CC}_{\mathrm{i}}\right.\right.$, then factor $A_{i}$ is possessed to the class of II and evaluative manners of factor $A_{i}$ is suggested with the possible of high danger. If we have $\left(0.4,0.6\right.$ [ $\in \mathrm{CC}_{\mathrm{i}}$, then factor $A_{i}$ is possessed to the class of III and evaluative manners of factor $A_{i}$ is suggested with the possible of low danger. If we have $\left(0.6,0.8\left[\in \mathrm{CC}_{\mathrm{i}}\right.\right.$, then factor $A_{i}$ is possessed to the class of IV and evaluative manners of factor $A_{i}$ and evaluative manners is suitable and acceptable. If we have $\left(0.8,1\left[\in \mathrm{CC}_{\mathrm{i}}\right]\right.$, then factor $A_{i}$ is possessed to class $V$ and evaluative manners of factor $A_{i}$ and it is suitable and acceptable for suggestion. According to Table 1 and rules of decision making, we can use verbal variable to describe present evaluative manner of every factor. In addition, if both factors possess to a similar class, closeness coefficient is used for determination of their ranking. The following steps explain details of our implementation.

\section{Algorithm I}

Step 1: Set up decision makers' committee and determine evaluative criteria,

Step 2: Select the verbal variable, suitable for comparative weights of criteria and verbal relations for factors,

Step 3: pluralize weights of criteria to get fuzzy weight $\tilde{w}_{j}, C_{j}$, and continue running to achieve collective fuzzy rate of $\tilde{x}_{i j}$ factor $A_{i}$ corresponding to $C_{j}$,

Step 4: Construct fuzzy decision-making matrix and normalize them,

Step 5: Construct weighted fuzzy decision-making matrix,

Step 6: Evaluate FPIS and FNIS,

Step 7: Calculate approximate distance of every facto from FPIS to FNIS,

Step 8: Calculate closeness coefficient of every factor,

Step 9: Evaluate every factor and distinguish regularity of all factors' ranking.

\section{Case study}

The case study of this paper uses 9 important factors for reducing fuel consumption as follows,

1. Airy traffic

2. Airy weight

3. Flight distance and speed

4. Maintenance and reparation

5. Characteristics of operation and flight dynamic
6. Role of technology in designing aircraft

7. Characteristics of aerodynamics

8. Updating pro-systems of aircraft

9. Renewing airy armada 
A comprehensive brain storming among decision makers yields the following criteria,

1.Under authorization

2.Price

3.Facility in demodulation

4.Need to time
5.Legal limitations

6.Existence of necessary instruments

7.Existence of necessary knowledge

All effective factors in reducing fuel consumption in terms of recognized criteria are weighted by expert. With regard to criterions' qualitative aspect, this weighting is fulfilled by verbal and fuzzy variables. Fig. 3 shows the principle model of the most effective selection method in reducing fuel consumption based on the distinguished criteria.

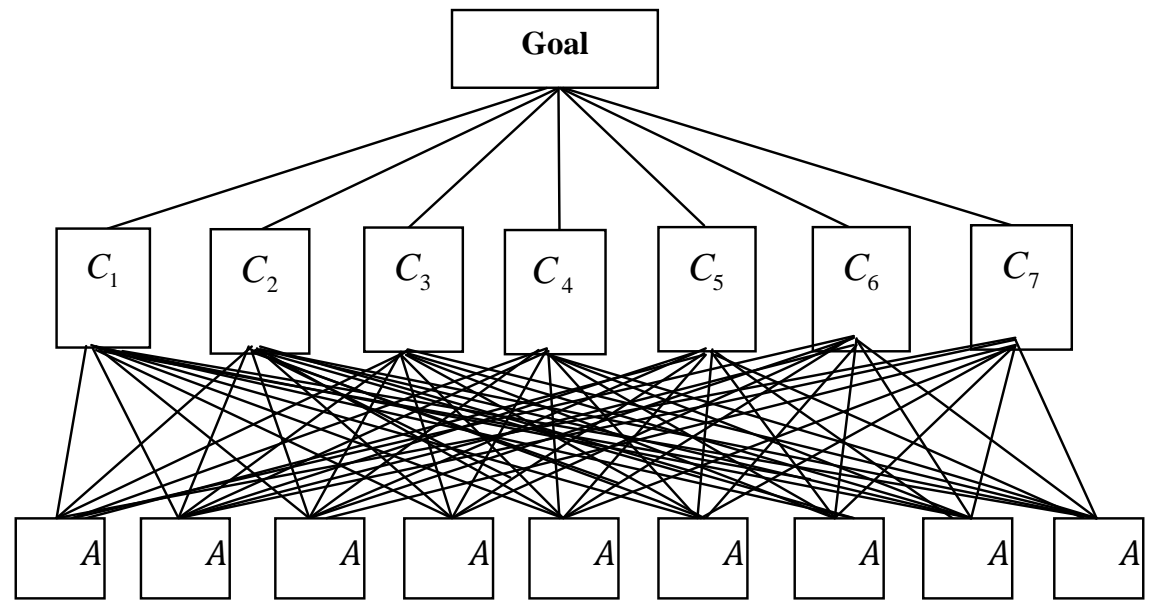

Fig. 3. Suggested model

Now, we implement the proposed multi-criteria method using triangular numbers for the case study of this paper. We have used ten decision makers to get their idea about different alternatives. Table 2 summarizes the results of the ranking. Table 3 demonstrates the ranking of alternative and criteria and Table 4 shows the evaluation of nine factors.

Table 2

Experts' assessment about importance of the criteria

\begin{tabular}{rrrrrrrrrrr}
\hline & D1 & D2 & D3 & D4 & D5 & D6 & D7 & D8 & D9 & D10 \\
\hline C1 & H & H & H & VH & H & H & H & VH & M & VH \\
C2 & VH & VH & VH & VH & VH & H & VH & VH & VH & VH \\
C3 & VH & H & VH & VH & H & H & VH & H & H & VH \\
C4 & H & H & H & VH & H & H & H & VH & M & VH \\
C5 & M & VH & VH & VH & VH & H & M & VH & VH & VH \\
C6 & H & H & H & VH & H & H & H & VH & VH & VH \\
C7 & VH & VH & M & M & H & VH & M & VH & VH & H \\
\hline
\end{tabular}

Table 3

Fuzzy decision matrix and fuzzy weights of present criteria

\begin{tabular}{rcccccccc}
\hline & C1 & C2 & C3 & C4 & C5 & C6 & C7 \\
\hline A1 & $(7,8,9)$ & $(4,6.5,9)$ & $(1,3.5,6)$ & $(4,6.2,9)$ & $(7,8,9)$ & $(7,8,9)$ & $(7,8,9)$ \\
A2 & $(7,8.6,10)$ & $(7,8,9)$ & $(4,5,6)$ & $(7,8.4,10)$ & $(7,8,9)$ & $(4,7,10)$ & $(7,8.1,9)$ \\
A3 & $(1,3.2,6)$ & $(1,3.5,6)$ & $(7,8,9)$ & $(4,7.7,9)$ & $(7,8,9)$ & $(7,8,9)$ & $(1,6.8,9)$ \\
A4 & $(4,6.6,10)$ & $(7,8,9)$ & $(7,8,9)$ & $(4,8.5,9)$ & $(7,8.5,10)$ & $(7,8.5,10)$ & $(4,7.1,9)$ \\
A5 & $(4,5,6)$ & $(4,5,6)$ & $(4,5.6,9)$ & $(4,7.7,9)$ & $(7,8,9)$ & $(7,8,9)$ & $(7,8.1,9)$ \\
A6 & $(4.7 .7,90$ & $(7,8,9)$ & $(7,8,9)$ & $(7,8,9)$ & $(7,8.5,10)$ & $(7,8.6,10)$ & $(1,6.5,9)$ \\
A7 & $(1,2.9,9)$ & $(7,8.5,9)$ & $(7,8,9)$ & $(4,7.4,10)$ & $(7,8.8,10)$ & $(7,8,9)$ & $(4,7.4,9)$ \\
A8 & $(1,5.6,10)$ & $(4,7.4,9)$ & $(1,3.5,6)$ & $(4,5.9,9)$ & $(7,8.3,10)$ & $(4,5.3,9)$ & $(8,9,10)$ \\
A9 & $(4,7,10)$ & $(8,9,10)$ & $(4,6.5,9)$ & $(7,8.4,10)$ & $(7,8.5,10)$ & $(4,6.2,9)$ & $(8,9,10)$ \\
\hline Weight & $(0.7,0.84,1)$ & $(0.4,0.81,1)$ & $(0.4,0.8,1)$ & $(0.7,0.86,1)$ & $(0.7,0.89,1)$ & $(0.4,0.8,1)$ & $(0.4,0.77,1)$ \\
\hline
\end{tabular}


Table 4

Evaluation of 9 factors in reducing fuel consumption

\begin{tabular}{|c|c|c|c|c|c|c|c|c|c|c|c|}
\hline \multirow{2}{*}{ Criteria } & \multirow{2}{*}{ Alternatives } & \multicolumn{10}{|c|}{ Decision makers (Experts) } \\
\hline & & $\mathrm{D} 1$ & $\mathrm{D} 2$ & D3 & D4 & D5 & D6 & D7 & D8 & D9 & D10 \\
\hline \multirow{10}{*}{ 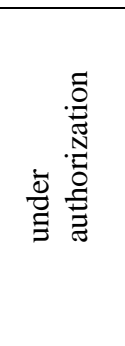 } & A1 & $\mathrm{G}$ & $\mathrm{G}$ & $\mathrm{G}$ & $\mathrm{G}$ & $\mathrm{G}$ & $\mathrm{G}$ & $\mathrm{G}$ & $\mathrm{G}$ & $\mathrm{G}$ & $\mathrm{G}$ \\
\hline & A2 & G & VG & VG & G & VG & VG & VG & G & VG & G \\
\hline & A3 & M & $\mathrm{P}$ & $\mathrm{P}$ & M & $\mathrm{P}$ & $\mathrm{P}$ & $\mathrm{M}$ & $\mathrm{P}$ & $\mathrm{P}$ & M \\
\hline & A4 & VG & M & $\mathrm{M}$ & VG & $\mathrm{M}$ & $\mathrm{M}$ & $\mathrm{M}$ & VG & $\mathrm{M}$ & VG \\
\hline & A5 & M & M & M & M & M & M & M & M & M & M \\
\hline & A6 & G & $\mathrm{G}$ & $\mathrm{G}$ & $\mathrm{G}$ & $\mathrm{G}$ & $\mathrm{G}$ & $\mathrm{G}$ & $\mathrm{M}$ & G & G \\
\hline & A7 & $\mathrm{P}$ & $\mathrm{P}$ & $\mathrm{P}$ & $\mathrm{M}$ & $\mathrm{P}$ & $\mathrm{P}$ & $\mathrm{P}$ & G & $\mathrm{P}$ & $\mathrm{P}$ \\
\hline & A8 & VG & VG & VG & VG & VG & VG & VG & $\mathrm{P}$ & VG & VG \\
\hline & A9 & VG & $\mathrm{M}$ & VG & $\mathrm{M}$ & VG & $\mathrm{M}$ & $\mathrm{M}$ & VG & $\mathrm{M}$ & VG \\
\hline & A1 & M & $\mathrm{G}$ & $\mathrm{G}$ & M & $\mathrm{M}$ & $\mathrm{G}$ & $\mathrm{M}$ & G & $\mathrm{G}$ & $\mathrm{M}$ \\
\hline \multirow{9}{*}{. } & A2 & G & $\mathrm{G}$ & G & $\mathrm{G}$ & $\mathrm{G}$ & $\mathrm{G}$ & $\mathrm{G}$ & $\mathrm{G}$ & $\mathrm{G}$ & G \\
\hline & A3 & M & $\mathrm{P}$ & $\mathrm{P}$ & M & $\mathrm{P}$ & M & M & $P$ & $\mathrm{P}$ & $\mathrm{M}$ \\
\hline & A4 & G & G & G & G & G & $\mathrm{G}$ & G & G & G & G \\
\hline & A5 & M & M & M & M & $\mathrm{M}$ & M & M & M & $\mathrm{H}$ & $\mathrm{H}$ \\
\hline & A6 & G & G & G & G & $\mathrm{G}$ & $\mathrm{G}$ & G & G & G & G \\
\hline & A7 & G & VG & $\mathrm{G}$ & VG & VG & $\mathrm{G}$ & G & VG & VG & G \\
\hline & A8 & VG & G & VG & VG & G & VG & $\mathrm{G}$ & VG & G & VG \\
\hline & A9 & VG & VG & VG & VG & VG & VG & VG & VG & VG & VG \\
\hline & A1 & $\mathrm{M}$ & $\mathrm{P}$ & $\mathrm{P}$ & $\mathrm{M}$ & $\mathrm{P}$ & M & $\mathrm{M}$ & $\mathrm{P}$ & $\mathrm{P}$ & M \\
\hline \multirow{9}{*}{ 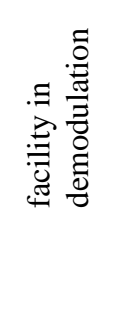 } & A2 & $\mathrm{M}$ & M & M & M & $\mathrm{M}$ & M & $\mathrm{M}$ & $\mathrm{M}$ & M & $\mathrm{M}$ \\
\hline & A3 & $\mathrm{G}$ & $\mathrm{G}$ & G & $\mathrm{G}$ & $\mathrm{G}$ & G & G & $\mathrm{G}$ & $\mathrm{G}$ & G \\
\hline & A4 & G & G & G & $\mathrm{G}$ & $\mathrm{G}$ & $\mathrm{G}$ & $\mathrm{G}$ & G & G & G \\
\hline & A5 & G & M & $\mathrm{M}$ & $\mathrm{G}$ & $\mathrm{M}$ & $\mathrm{G}$ & $\mathrm{G}$ & $\mathrm{M}$ & M & G \\
\hline & A6 & G & G & G & G & G & G & G & G & G & G \\
\hline & A7 & $\mathrm{G}$ & $\mathrm{G}$ & G & $\mathrm{G}$ & G & G & $\mathrm{G}$ & $\mathrm{G}$ & $\mathrm{G}$ & G \\
\hline & A8 & $\mathrm{M}$ & $\mathrm{P}$ & M & $\mathrm{P}$ & $\mathrm{M}$ & $\mathrm{P}$ & $\mathrm{P}$ & $\mathrm{M}$ & $\mathrm{P}$ & $\mathrm{M}$ \\
\hline & A9 & $\mathrm{M}$ & $\mathrm{P}$ & M & $\mathrm{P}$ & $\mathrm{P}$ & $\mathrm{M}$ & $\mathrm{M}$ & $\mathrm{P}$ & $\mathrm{P}$ & $\mathrm{M}$ \\
\hline & A1 & M & G & G & M & G & M & $\mathrm{M}$ & $\mathrm{M}$ & $\mathrm{G}$ & M \\
\hline \multirow{6}{*}{ 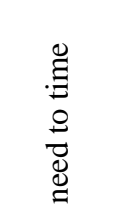 } & A2 & $\mathrm{G}$ & VG & VG & G & VG & G & G & $\mathrm{G}$ & VG & G \\
\hline & A3 & $\mathrm{G}$ & G & G & G & G & G & M & $\mathrm{M}$ & G & G \\
\hline & A4 & $\mathrm{M}$ & G & G & G & $\mathrm{M}$ & G & $\mathrm{M}$ & $\mathrm{M}$ & G & $\mathrm{M}$ \\
\hline & A5 & $\mathrm{G}$ & G & G & G & G & G & M & $\mathrm{M}$ & G & G \\
\hline & A6 & $\mathrm{G}$ & G & G & G & $\mathrm{G}$ & G & $\mathrm{G}$ & $\mathrm{G}$ & G & G \\
\hline & A7 & M & VG & M & VG & $\mathrm{M}$ & VG & VG & VG & VG & $\mathrm{M}$ \\
\hline \multirow{12}{*}{ 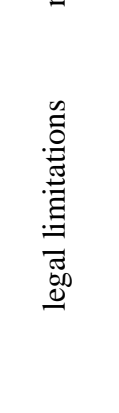 } & A8 & M & $\mathrm{M}$ & M & G & $\mathrm{M}$ & G & $\mathrm{M}$ & $\mathrm{M}$ & G & $\mathrm{M}$ \\
\hline & A9 & $\mathrm{G}$ & VG & G & G & VG & G & G & $\mathrm{G}$ & VG & G \\
\hline & A1 & G & $\mathrm{G}$ & G & $\mathrm{G}$ & G & $\mathrm{G}$ & G & G & G & G \\
\hline & A2 & $\mathrm{G}$ & G & G & G & G & $\mathrm{G}$ & G & $\mathrm{G}$ & G & G \\
\hline & A3 & $\mathrm{G}$ & $\mathrm{G}$ & $\mathrm{G}$ & $\mathrm{G}$ & G & $\mathrm{G}$ & $\mathrm{G}$ & $\mathrm{G}$ & $\mathrm{G}$ & G \\
\hline & A4 & G & VG & G & VG & G & VG & G & $\mathrm{G}$ & VG & G \\
\hline & A5 & $\mathrm{G}$ & $\mathrm{G}$ & G & $\mathrm{G}$ & G & $\mathrm{G}$ & $\mathrm{G}$ & $\mathrm{G}$ & $\mathrm{G}$ & G \\
\hline & A6 & $\mathrm{G}$ & $\mathrm{G}$ & $\mathrm{G}$ & $\mathrm{G}$ & G & G & $\mathrm{G}$ & $\mathrm{G}$ & $\mathrm{G}$ & G \\
\hline & A7 & VG & VG & VG & VG & G & VG & VG & VG & VG & VG \\
\hline & A8 & $\mathrm{G}$ & VG & $\mathrm{G}$ & $\mathrm{G}$ & $\mathrm{G}$ & VG & $\mathrm{G}$ & G & VG & G \\
\hline & A9 & $\mathrm{G}$ & VG & VG & $\mathrm{G}$ & VG & G & VG & VG & VG & G \\
\hline & A1 & $\mathrm{G}$ & $\mathrm{G}$ & G & G & $\mathrm{G}$ & $\mathrm{G}$ & $\mathrm{G}$ & G & $\mathrm{G}$ & G \\
\hline \multirow{8}{*}{ 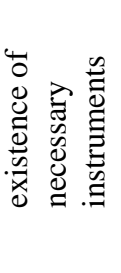 } & A2 & M & VG & VG & VG & $\mathrm{M}$ & M & VG & VG & VG & $\mathrm{M}$ \\
\hline & A3 & G & G & G & $\mathrm{G}$ & G & G & $\mathrm{G}$ & G & G & G \\
\hline & A4 & $\mathrm{G}$ & VG & VG & G & VG & G & VG & VG & VG & G \\
\hline & A5 & G & G & G & G & G & G & $\mathrm{G}$ & G & G & G \\
\hline & A6 & G & VG & VG & VG & G & G & VG & VG & VG & G \\
\hline & A7 & $\mathrm{G}$ & G & G & $\mathrm{G}$ & G & G & $\mathrm{G}$ & G & G & G \\
\hline & A8 & M & M & $\mathrm{M}$ & M & $\mathrm{M}$ & M & M & $\mathrm{M}$ & $\mathrm{M}$ & $\mathrm{M}$ \\
\hline & A9 & $\mathrm{G}$ & M & $\mathrm{G}$ & M & $\mathrm{G}$ & M & M & M & M & G \\
\hline \multirow{9}{*}{ 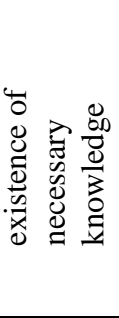 } & A1 & $\mathrm{G}$ & $\mathrm{G}$ & $\mathrm{G}$ & $\mathrm{G}$ & G & G & $\mathrm{G}$ & $\mathrm{G}$ & G & G \\
\hline & A2 & $\mathrm{G}$ & $\mathrm{G}$ & G & $\mathrm{G}$ & G & G & VG & $\mathrm{G}$ & G & G \\
\hline & A3 & $\mathrm{G}$ & M & $\mathrm{P}$ & G & G & G & $\mathrm{G}$ & $\mathrm{M}$ & G & G \\
\hline & A4 & $\mathrm{G}$ & $\mathrm{G}$ & $\mathrm{M}$ & $\mathrm{M}$ & $\mathrm{G}$ & M & $\mathrm{G}$ & $\mathrm{G}$ & $\mathrm{G}$ & G \\
\hline & A5 & $\mathrm{G}$ & $\mathrm{P}$ & $\mathrm{G}$ & $\mathrm{G}$ & $\mathrm{G}$ & M & $\mathrm{G}$ & $\mathrm{G}$ & M & G \\
\hline & A6 & G & M & $\mathrm{M}$ & $\mathrm{G}$ & $\mathrm{G}$ & $\mathrm{M}$ & $\mathrm{P}$ & $\mathrm{G}$ & $\mathrm{G}$ & G \\
\hline & A7 & $\mathrm{G}$ & G & $\mathrm{G}$ & M & $\mathrm{G}$ & $\mathrm{G}$ & $\mathrm{G}$ & G & $\mathrm{G}$ & M \\
\hline & A8 & VG & VG & VG & VG & VG & VG & VG & VG & VG & VG \\
\hline & A9 & VG & VG & VG & VG & VG & VG & VG & VG & VG & VG \\
\hline
\end{tabular}


Table 5

Calculation of $d_{i}^{+}, d_{i}^{-}$and $C C_{i}$

\begin{tabular}{llllcc}
\hline & Description & $d_{i}^{+}$ & $d_{i}^{-}$ & $d_{i}^{+}+d_{i}^{-}$ & $C C_{i}$ \\
\hline A3 & Flight distance and speed & 4.03 & 2.84 & 6.87 & 0.518 \\
A2 & Airy weight & 4.3 & 3.28 & 6.68 & 0.5 \\
A1 & Airy traffic & 3.57 & 3.14 & 6.71 & 0.499 \\
A4 & Maintenance and repair & 3.47 & 3.46 & 6.93 & 0.491 \\
A5 & Characteristics of operation and flight dynamic & 3.7 & 3.08 & 6.78 & 0.481 \\
A7 & Role of technology in designing aircraft & 3.65 & 3.39 & 7.04 & 0.471 \\
A6 & Characteristics of aerodynamics & 3.57 & 3.2 & 6.77 & 0.458 \\
A8 & Updating pro-systems of aircraft & 3.65 & 3.6 & 7.3 & 0.454 \\
A9 & Renewing airy armada & 3.37 & 3.63 & 7 & 0.413 \\
\hline
\end{tabular}

As we can observe from Table 5, flight distance and speed represents the best alternative of ranking followed by airy weight and traffic, maintenance. Other alternatives such as characteristics of operation and flight dynamic, role of technology in designing aircraft, aerodynamics, updating prosystems of aircraft and renewing airy armada come after with lower priorities.

\section{Conclusion}

In this paper, we have studied different factors on reduction of fuel consumption and proposed a fuzzy decision making technique to rank them. The proposed model of this paper gathered decision makers' opinions in verbal forms and, using triangular numbers, they were converted into regular fuzzy numbers. We have determined nine different factors affecting the fuel consumption and the results of the implementation of our proposed model indicated that flight distance and speed is the most important factors affecting the fuel consumption. The other important factors are airy weight and traffic, a good maintenance and repair, characteristics of operation and flight dynamic, design, aerodynamic characteristics, update system of aircraft and renewing airy armada. The proposed model of this paper can be extended using some more sophisticated MCDM methods and we leave it for interested researchers as future work.

\section{Acknowledgment}

The authors would like to thank the anonymous referees for constructive comments made on the first draft of this paper, which helped us presenting better quality paper.

\section{References}

Bellman, B.E., \& Zadeh, L.A. (1970). Decision-making in a fuzzy environment. Management Science, 17 (4), 141-164.

Brewer, G. D. (1991). Hydrogen Aircraft Technology, CRC Press, Boca Raton, Florida, USA, ISBN 0-84935838-8.

Chen, C.T. (2000). Extensions of the TOPSIS for group decision-making under fuzzy environment. Fuzzy Sets and Systems, 114, 1-9.

Cook, R.L. (1992). Expert systems in purchasing applications and development. International Journal of Purchasing and Management, 18, 20-27.

Delgado, M., Verdegay, J.L., \& Vila, M.A. (1992). Linguistic decision-making models. International Journal of intelligent Systems, 7, 479-492.

Douglas, A. R. et al. (1991). The atmospheric effects of stratospheric aircraft: a current consensus. NASA reference publication 1251.

Grahame. W., \& Rodriquez, A. M. (1951). The characteristics of fuel motion which affect airplane dynamics. DOUGLAS AIRCRAFT CO INC SANTA MONICA CALIF, Accession Number: ADA073847.

Herrera, F., \& Herrera-Viedma, E. (2000). Linguistic decision analysis: Steps for solving decision problems under linguistic information. Fuzzy Sets and Systems, 115, 67-82. 
Herrera, F., Herrera-Viedma, E., \& Verdegay, J.L. (1996). A model of consensus in group decision making under linguistic assessments. Fuzzy Sets and Systems, 78, 73-87.

Hwang, C.L., \& Yoon, K. (1981). Multiple Attributes Decision Making Methods and Applications. Springer, New York.

Kaufmann. A., \& Gupta, M.M. (1991). Introduction to Fuzzy Arithmetic: Theory and Applications. Van Nostrand Rein-hold, New York.

Lister, D. H. (1992). Aircraft emissions and the environment. Paper from an IMechE Aerospace Industries Division Seminar on Twenty-first century aero engine design 1992 scenario.

Marchetti, C. (1982). When will hydrogen come? Working paper WP-82-123, IIASA, Laxenburg, Austria, November.

Ohsfeldt, M., \& Thrasher, T. (2007). Quantifying the relationship between air traffic management inefficiency, fuel burn and air pollutant emission, Air traffic management seminar.

Reynolds, T. G. (2008). Analysis of lateral flight inefficiency in global air traffic management, $8^{\text {th }}$ AIAA Aviation Technology, Integration and Operations Conference $26^{\text {th }}$ Congress of the International Council of Aeronautical Sciences Anchorage, Alaska, USA, 14-19 September 2008, Institute for Aviation and the Environment.

Van der Burgt, M, et al. (1989). The SHELL middle distillate process. SHELL selected paper.

Williams, V., \& Noland, R. B. (2005). Variability of contrail formation conditions and the implications for policies to reduce the climate impacts of aviation, Transportation Research Part D: Transport and Environment, 10(4), 269-280.

Williams, V., Noland, R. B., \& Toumi, R. (2002). Reduce the climate change impacts of aviation by restricting cruise altitudes, Transportation Research Part D: Transport and Environment. 5(6), 187-198. 